\title{
Rivalry between Stink Bug Females in a Vibrational Communication Network
}

\author{
Andrej Čokl ${ }^{1}$ - Aline Moreira Dias ${ }^{2}$. \\ Maria Carolina Blassioli Moraes ${ }^{3}$. \\ Miguel Borges $^{2,3}$ • Raul Alberto Laumann ${ }^{2,3}$
}

Revised: 12 September 2017 / Accepted: 29 November 2017 /

Published online: 18 December 2017

(C) Springer Science+Business Media, LLC, part of Springer Nature 2017

\begin{abstract}
In the field, male pheromone attracts stink bugs to meet on the same plant and triggers females to call a male by the emission of the calling song. As first among Pentatomidae we describe female rivalry in Chinavia impicticornis, C. ubica and Euschistus heros. Rivalry starts in C. impicticornis by synchronized exchange of the first type of the female calling song pulse trains and proceeds by one of them either to change pulse trains from the first to the second type or to produce readily repeated single pulses. Both reactions either inhibit calling of the rival female or trigger her to respond by alternation with the second type of the calling song pulse trains. Female rivalry in $C$. ubica differs by the emission of the rival song that replaces alternation with the second type of the calling song typical for $C$. impicticornis. E. heros females synchronize pulses of the calling song duets and induce emission of the female rival song by one of them that partly inhibits singing of the other. These competitive interactions in Chinavia species reduce the proportion of couples when compared with single couples on a plant. Contrary to both Chinavia species, E. heros female rivalry does not inhibit male response, male signals overlap female emissions and create complex vibrations with modified amplitude modulation pattern caused by interference.
\end{abstract}

Electronic supplementary material The online version of this article (https://doi.org/10.1007/s10905-0179651-z) contains supplementary material, which is available to authorized users.

Andrej Čokl

andrej.cokl@nib.si

1 Department of Organisms and Ecosystems Research, National Institute of Biology, Večna pot 111, 1000 Ljubljana, Slovenia

2 Programa de Pós-graduação em Zoologia, Departamento de Zoologia, Instituto de Biologia, Universidade de Brasília, Campus Universitário Darcy Ribeiro, Brasília CEP 70910-900, Brazil

3 Laboratório de Semioquímicos, EMBRAPA Recursos Genéticos e Biotecnologia, Avenida W5 Norte (Final), Brasilia 70770-900, Brazil 
Keywords Calling interactions $\cdot$ female duets $\cdot$ signal synchronization $\cdot$ signal modification $\cdot$ mating behaviour

\section{Introduction}

Animal communication usually includes more than just sender and receiver because other conspecific or heterospecific individuals could interfere with interchanged signals. This multiple player communication often happens in a communication network with several conspecific or heterospecific senders, rivals or exploiters that eavesdrop on signals (McGregor and Peake 2000; Bradbury and Vehrencamp 2011). This network context has been considered and studied in social group living animals and insects (Pinter-Wollman et al. 2014), but in sexual interactions, only emitter-receiver dyads have been usually contemplated (Virant-Doberlet et al. 2014).

With more than 2800 species the plant-dwelling stink bugs of the subfamily Pentatominae (Heteroptera: Pentatomidae) represent a smaller but economically important group of insects with well investigated biology, ecology, and feeding habits (Grazia et al. 2015). Mating behavior is characterized by multimodal communication with chemical (Borges and Blassioli-Moraes 2017) and vibratory (Čokl et al. 2017) signals. Male pheromone attracts mates to gather on the same plant (Borges et al. 1987) and triggers female calling by plant transmitted vibrational signals (Zgonik and Čokl 2014). Species and gender specific plant-transmitted signals have been described in more than 36 pentatomine species (Čokl et al. 2017 ) as result of recording emissions of one or two males placed together with a single female on a non-resonant substrate (usually loudspeaker membrane) or on a plant. Songs have been determined according to the mating behavioral context as calling, courtship, copulatory, repelling and rival songs. The latter were identified and described only for males competing to copulate with the same female (Čokl et al. 2000, 2011; Blassioli-Moraes et al. 2005; Bagwell et al. 2008).

Questions concerning rivalry or any vibratory interaction between females have not been investigated so far although aggregate distributions of males and females of different species have been observed on the same plant in the field (Higuchi 1992; Tillman et al. 2009; Panizzi 2013; Panizzi and Lucini 2016; Aquino 2016). We investigated vibratory interactions during reproductive behavior of three pentatomine species, Chinavia impicticornis (Stål 1872), C. ubica (Rolston 1983) and Euschistus heros (F. 1978) in a social environment where females compete to copulate with a male. Sympatric $C$. impicticornis and $C$. ubica mates feed and mate in the field on the same host plants (Panizzi et al. 2000) and recent investigation of their vibratory communication suggests that hybridisation between both species is prevented within the calling phase of mating behavior (Laumann et al. 2016). E. heros females emit one type of the calling song signals (Blassioli-Moraes et al. 2005; Kavčič et al. 2013) that often overlap male vibratory responses. Interference significantly changes the temporal and frequency characteristics of masked vibrations (Čokl et al. 2015).

We hypothesized that females in a group, as males, compete to get access to males. Our prediction is that in competition situations females express rivalry by the exchange of vibratory rival signals and/or by physical interactions before or during courtship behavior. To confirm or reject this hypothesis we placed on a plant two or three 
C. impicticornis, C. ubica or E. heros females with a single conspecific male, recorded their vibratory emissions and observed their behavior.

\section{Methods}

\section{Insects, Plants and Growth Conditions}

Experiments were conducted with at least 10 days old adults of $C$. impicticornis, C. ubica and E. heros from colonies maintained at the Laboratório de Semioquímicos of EMBRAPA Recursos Genéticos e Biotecnologia, Brasilia (DF), Brazil. Insects were reared in acclimatized rooms $\left(26 \pm 1{ }^{\circ} \mathrm{C}, 65 \pm 10 \% \mathrm{RH}\right.$, photoperiod 06:00-20:00) in eight $\mathrm{L}$ transparent plastic containers and fed with a diet composed of water, offered in plastic pots with cotton wad, green bean pods (Phaseolus vulgaris L.), dry soybean seeds (Glycine max L.), sunflower seeds (Helianthus annuus L.) and raw peanuts (Arachis hypogaea L.). The diet was replaced three times a week. Males and females were separated after imaginal moult and maintained in separated rooms until they have been used in experiments. Soybean plants were grown in green house in sterilized soil in $20 \mathrm{~cm}$ high and $15 \mathrm{~cm}$ diameter pots. Experiments were conducted on soybean plants of V3 stage (Fehr et al. 1971) with 16-27 high stem, two unifoliate (about $7 \times 7 \mathrm{~cm}$ ) and two trifoliate (about $6 \times 8 \mathrm{~cm}$ ) leaves. New fresh plants were used for each species and were changed every 5 to 10 tested groups.

\section{Recording}

All experiments were conducted in a sound insulated room during May and August 2016 between 08:00 and 16:30 h. Vibrational signals were registered by a portable digital laser vibrometer (PDV-100, Polytec GmbH, Waldbronn, Germany) from a reflective tape (diameter $<4 \mathrm{~mm}^{2}$ ) fixed on the stem $(4 \mathrm{~cm}$ above the soil) of plants in pots placed on a shock-proof table. The laser beam was oriented perpendicularly to the stem. Laser recorded plant vibrations were digitized by a sound card (24-bit, 96- kHz, 100-dB signal-to-noise ratio, Sound Blaster Extigy, Creative Laboratories Inc., Milpitas, California, USA) and stored on a computer by the use of Cool Edit Pro 2.0 software (Syntrillium Software 2001 - Fort Wayne, Indiana, USA) for further analysis with Sound Forge, Version 6.0 (Sonic Foundry, Inc., Madison, California, USA) software.

\section{Vibrational Signal Analysis}

Songs produced by $C$. impicticornis and C. ubica are labelled according to terminology used by Laumann et al. (2016) as FS-1a or FS-1b for the first or the second type of female calling song pulse trains respectively, and as MS-1 or MS-2 for the male first and second song. E. heros female and male calling songs are labelled as FS-1 and MS-1 according to terminology used by Blassioli-Moraes et al. (2005). The newly recorded female rival song is labelled as FRS.

Songs were described by temporal and spectral characteristics of their basic units. Pulses are defined as unitary homogeneous parcels of vibration of finite duration (Broughton 1963) and constitute E. heros FS-1 song. The first and second type of 
C. impicticornis and C. ubica FS-1 song are characterized by pulses grouped into distinct pulse trains. Pulses are described by their duration (the time between signal onset and end when their amplitude reached the noise level), repetition time (the time between onsets of two sequential signals) and interval (the time between two sequential signals). Pulse train duration is described as the time between the onset of the first and end of the last pulse, repetition time as the time between onsets of the first pulses of two sequential pulse trains and interval as the time between them. Signal frequency characteristics are described by their dominant frequency and frequency modulation (FM) measured from spectra and sonograms (FFT size 32,768, FFT overlap 99\%, smoothing window Blackman-Harris, and display range $60-80 \mathrm{~dB}$ ). FM is defined as upward or downward oriented frequency sweep and is expressed as the frequency difference measured at the signal onset and end divided by signal duration.

\section{Experimental Design}

Two or three females were placed on different leaves of a soybean plant and a conspecific male was added after they stopped moving. Each female or male was tested only once. Vibrational signals were recorded until the end of their emission. If no female calling songs were registered within $10 \mathrm{~min}$ we terminated the test and discarded insects of the group. Insects were monitored by direct observations and their behavior and vibratory signal emissions were registered in an electronic sheet considering the sequence of insects placed on a plant. Behavioral categories follow those described by Laumann et al. (2016) and are detailed in the Fig. 1.

Chinavia impicticornis

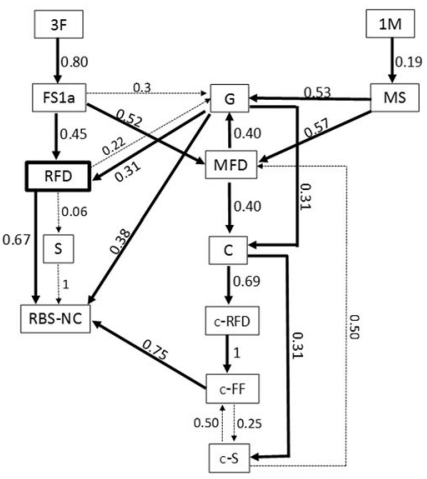

Chinavia ubica

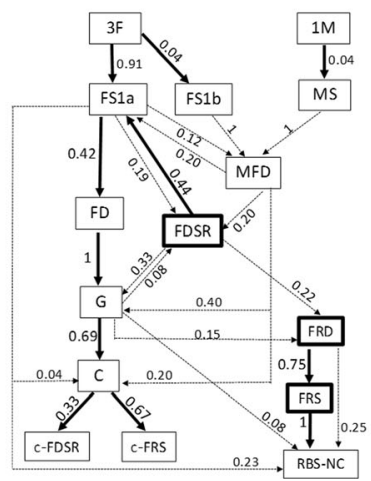

Euschsitus heros

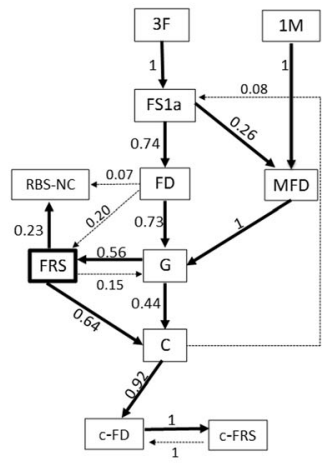

Fig. 1 Sequence of courtship and mating behaviour of C. impicticornis, C. ubica and E. heros groups of females and a male. Values near lines represent the probability of transitions between behaviours. Solid-line arrows indicate the significant transitions $(P<0.05)$ and dashed-line arrows the non-significant transitions $(P>0.05)$. Boxes represent behavioural categories. C - Copula, c-FD - Copulated and non-copulated Female Duet, c-FDSR copulated an non-copulated Female Duet with alternated FRS and FS-1a or FS-1b signals, cFRS - female rival song emitted by a non-copulated female in the presence of a copulated pair, c-RFD Female Duet Rivalry during copula, c-S - Female Solo calling in the presence of a copulated pair, FD - Female Duet, FDSR - Female Duet of alternated FRS with FS-1a or FS-1b signals, FF - Females Fight and aggression, FRD - Female Rivalry Duet with FRS signals, FRS - solo emission of FRS, FS1a - FS-1a, FS1b - FS-1b, G Group singing, MFD - Male and Female Duet, MS - MS-1, RBS-NC - Reproductive Behavior Stopped, No Copulation observed, RFD- Rival Duet in C. impicticornis by alternated FS-1a and FS-1b signals, S - Female Solo calling in a group 


\section{Data Analysis}

Data from 36 trials of C impicticornis, 24 of C. ubica and 19 of E. heros behavioral sequences were used to create the first-order Markovian transition matrix of the total frequency of transitions (i.e. moving from one behavioral step to the next). The repetition of a single behavior (self-transition) was not included in the records to avoid the possible influence of the relative weight of transitions between behaviors. Transition probabilities were calculated from the observed frequency of a transition between two events divided by the total number of occurrences of the first event (Haccou and Meelis 1992). The expected values of each transition were obtained by multiplying the total values of each column and row of the respective transition and dividing by total number of transitions observed (grand total) and the statistical significance of the individual transitions was evaluated by G-test at 5\% significance level. The results are shown graphically in ethograms.

Duetting Chinavia spp. females showed a clear one-to-one alternation of wellstructured and synchronized FS-1a signals. Mean values of temporal (duration, repetition time and interval) and spectral (dominant frequency and FM) pulse train or pulses parameters were calculated and compared between individuals of the same group by paired $t$-test. To check if females of both species synchronize alternated signals in a similar way the differences of pulse train parameters between individuals of a pair in a sequence of 15 signals of 8 pairs were analysed between species by ANOVA repeatedly measures. In addition, the variation coefficient of the differences between individuals were calculated and compared by a $t$-test. Alternation of FS-1a/VS-1b or FS-1b/FS-1b signals is less regular, without longer lasting fully developed duets that does not allow relevant statistical analysis. Inter-individual comparison of female rival signal parameters of each species were conducted by the use of repeatedly measured ANOVA and generalized linear models with Poisson distribution for number of pulses/pulse train. All analyses were performed in R software version 3.1.2 (R Development Core Team 2011).

\section{Results}

\section{Mating Behavior and Vibrational Interactions between Females and a Male}

Ethograms of Fig. 1 show different steps (phases) of mating behavior and types of vibratory song emissions.

In both Chinavia species the presence of a male on a plant triggered conspecific females to emit the calling song (FS-1) constituted by pulse trains of the first (FS-1a) and second (FS-1b) type (Laumann et al. 2016). FS-1a was recorded as the first emission in 29 of 36 tests in C. impicticornis and in 22 of 24 tests in C. ubica.

FS-1a as the first female emission changes gradually to FS-1b in C. impicticornis and C. ubica (Fig. 2); only in one test with C. ubica the female started to call by pulse trains of the FS-1b type. MS-1 song was in both Chinavia species recorded as the response to the female calling. The female/male duets (MFD) induced courtship and copulatory behavior $(C)$ or triggered the other female to enter singing in a group $(\mathrm{G})$ (Fig. 1). 
Female vibratory signal emissions produced during rivalry in a group differed in both Chinavia species. In C. impicticornis FS-1a emitted by one female induced female calling rivalry duets (RFD) (Figs. 1 and 2). Alternation with FS-1a and FS-1b signals silenced both the male and one of the rival females (S) and stopped the reproductive behavior (RBS-NC) (Fig. 1).

In C. ubica presence of the second female induced formation of a female FS-1 duet (FD) that evolved to insects singing in a group, including male signals (G) or to exchanging of different female signals (FDRS or FRD). Rivalry terminated with the

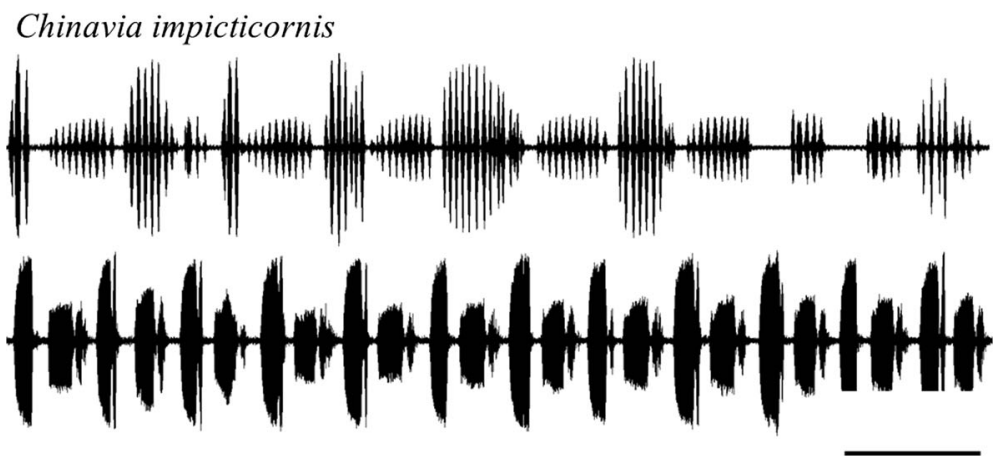

Chinavia ubica
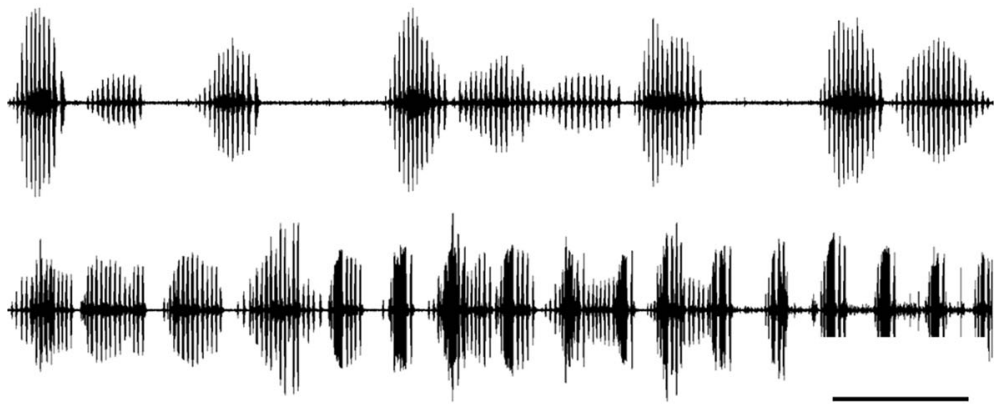

Euschistus heros

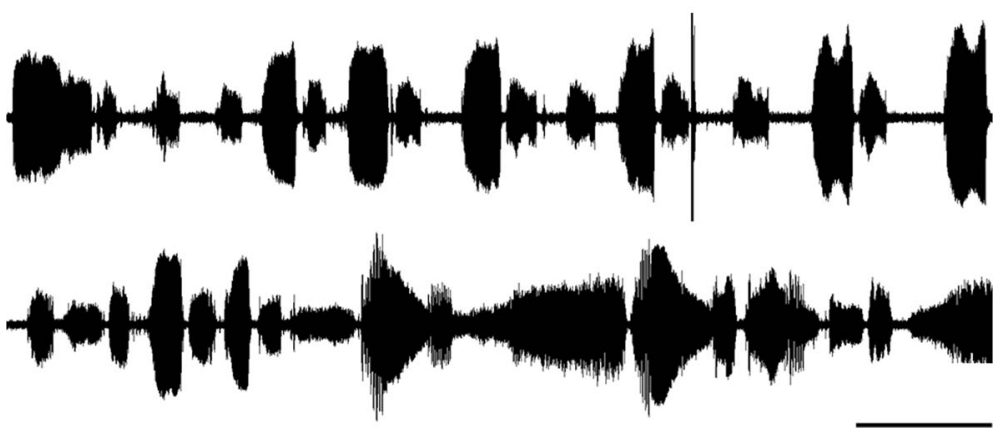

Fig. 2 Alternation of female calling signals in C. impicticornis (upper trace - FS-1a/FS-1a, lower trace - FS1b/FS-1b), C. ubica (upper trace - FS-1a/FS-1a, lower trace - FS-1b/FS-1b) and in E. heros (upper trace - non overlapped FS-1 pulses, lower trace - partly overlapped alternated FS-1 with MS-1 signals). Horizontal lines indicate $5 \mathrm{~s}$ 
emission of the rival song (FRS) with characteristic temporal and frequency structure (Figs. 1 and 2). The emission of FRS song silenced the rival female and the responding male. Consequently reproductive and copulatory behavior stopped (RBS-NC) (Fig. 1).

In $E$. heros vibratory interactions started with FS-1 emission in all observed groups. Compared to Chinavia species, E. heros females expressed less regular and strict pattern of rivalry (Fig. 1). Female calling induced male responses (MFD) and/or other female calling (FD) that all constituted singing in a group (G) (Fig. 1). Female calling duets either inhibited reproductive and copulatory behavior (RBS-NC) or induced FRS often emitted in a group (G) with the male (MFD).

Winning female usually copulated (C) after female/male duetting that followed rivalry. Copulation was observed in 15 pairs of 36 groups in C. impicticornis (41.67\%), 13 pairs of 24 groups in C. ubica $(54.17 \%)$ and in 15 pairs of 19 (78.94\%) groups in E. heros.

The female rivalry was occasionally recorded also after a pair copulated. It was expressed as FS-1 alternations in C. impicticornis (8 females of a group in 15 mating pairs, C-FDR) and/or as FRS emissions (C-FRS) in C. ubica (3 females of a group in 13 mating pairs) and $E$. heros (4 females of a group in 15 mating pairs) (Fig. 1). In addition, after a pair started to copulate the other female sang either alone (c-S) (8 females in 13 mattings in C. ubica, 4 females of 13 mattings in C. impicticornis) or in a duet with copulated one (C-FD) (12 female duets in 15 mattings in $E$. heros). In C. impicticornis, we observed female fight (FF) (Fig. 1) and physical attempt to separate the copulated pair (Online Resource ESM Videos 1, 2). If separation of copula by direct physical aggression succeeded, the aggressing female tried to push the other one out of the leaf and mating behavior was interrupted (RBS-NC) (Fig. 1).

\section{Female Rivalry Interactions}

In all three investigated species, female calling duets represent their first competitive interaction when on a plant with a single male (Fig. 2).

C. impicticornis female duets are expressed as synchronized alternations of FS-1a and/or FS-1b pulse trains. In fully developed analysed duets $(N=8)$ are FS-1a pulse trains exchanged in one-to-one fashion (Fig. 2) by adaptation of pulse train duration to intervals between consecutive rival female signals. Comparison of pulse train parameters of alternated signals has shown significant differences of pulse train duration in most C. impicticornis evaluated pairs (62.5\%) (Fig. 3).

Duetting with synchronized pulse trains terminated by one female that prolonged FS1-a pulse trains and disrupted them afterwards into a sequence of readily repeated pulses of different amplitudes that masked FS-1a pulse trains emitted by the other female (Fig. 4). Readily repeated FS-1a pulses either silenced the rival female or triggered her to change FS-1a to FS-1b type of pulse trains over various transitional forms (Fig. 4). FS-1b pulse trains inhibited emission of FS-1a signals and either silenced the rival female or triggered her to alternate with FS-1b pulse trains (Fig. 4). During female duetting, the male was silent until the "winning" female inhibited signalling of the rival one and produced again regular FS-1a pulse trains.

Simultaneously calling $C$. ubica females, like $C$. impicticornis, avoided FS-1a pulse train overlapping by adjusting their emission to intervals between consecutive signals produced by the duetting female (Fig. 2); in this case no significant temporal 


\section{C. impicticornis}
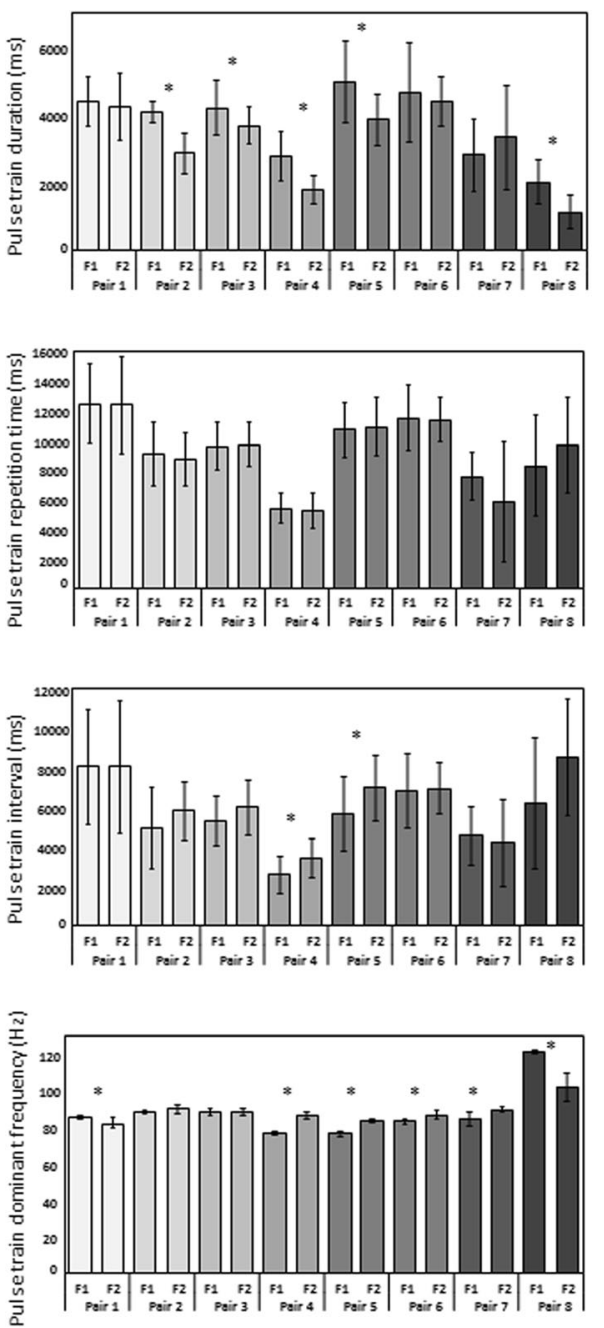

C. ubica
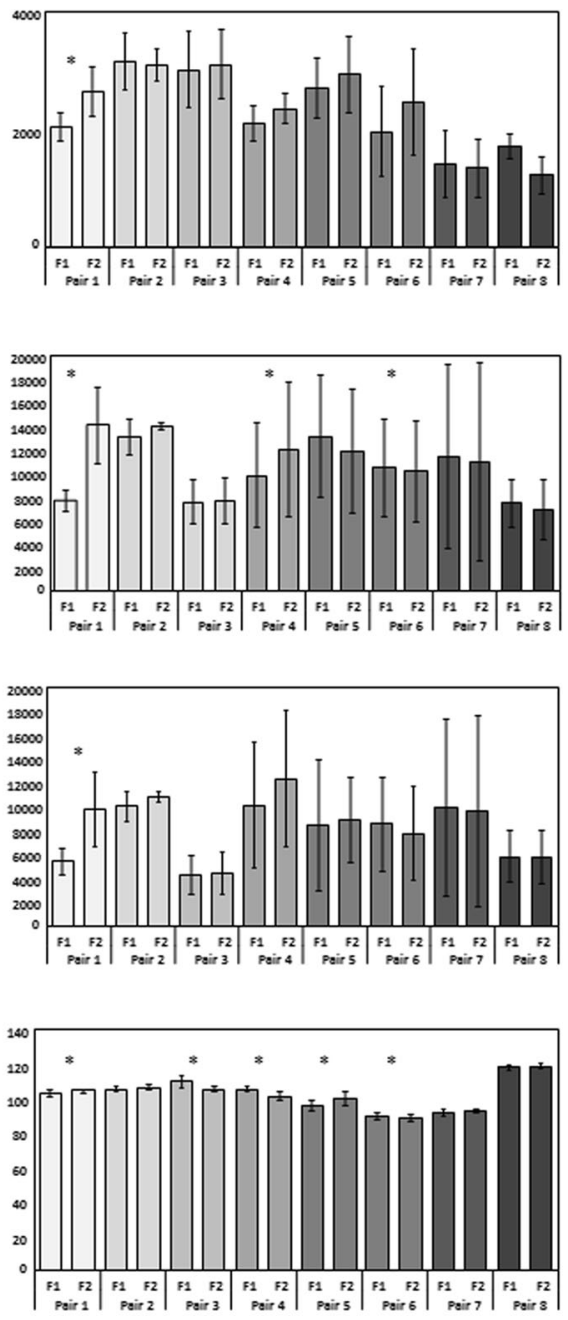

Fig. 3 Mean $( \pm \mathrm{SD})$ values of pulse train duration, repetition time, interval and dominant frequency parameters of C. impicticornis and C. ubica alternated FS-1a signals emitted. * indicates significant differences of parameters between females of the same pair (paired $t$-test $\mathrm{P}<0.05$ ), F1 - female 1 of a pair, F2 female 2 of the same pair

differences were observed in signals emitted by the females of the same pair (Fig. 3). Along alternation with FS-1a signals one female changed pulse trains from FS-1a to FS-1b type that either silenced the rival female (Fig. 2) or triggered her to emit the female rival song (FRS) (see below).

Significant differences of the mean dominant frequency were measured for alternated signals of the same pair in both species (Fig. 3).

Best structuration and less variability in the alternation of FS-1a signals were observed in C. impicticornis female interactions. Mean differences in pulse train duration and dominant frequency between individuals of the same pair were higher 
A
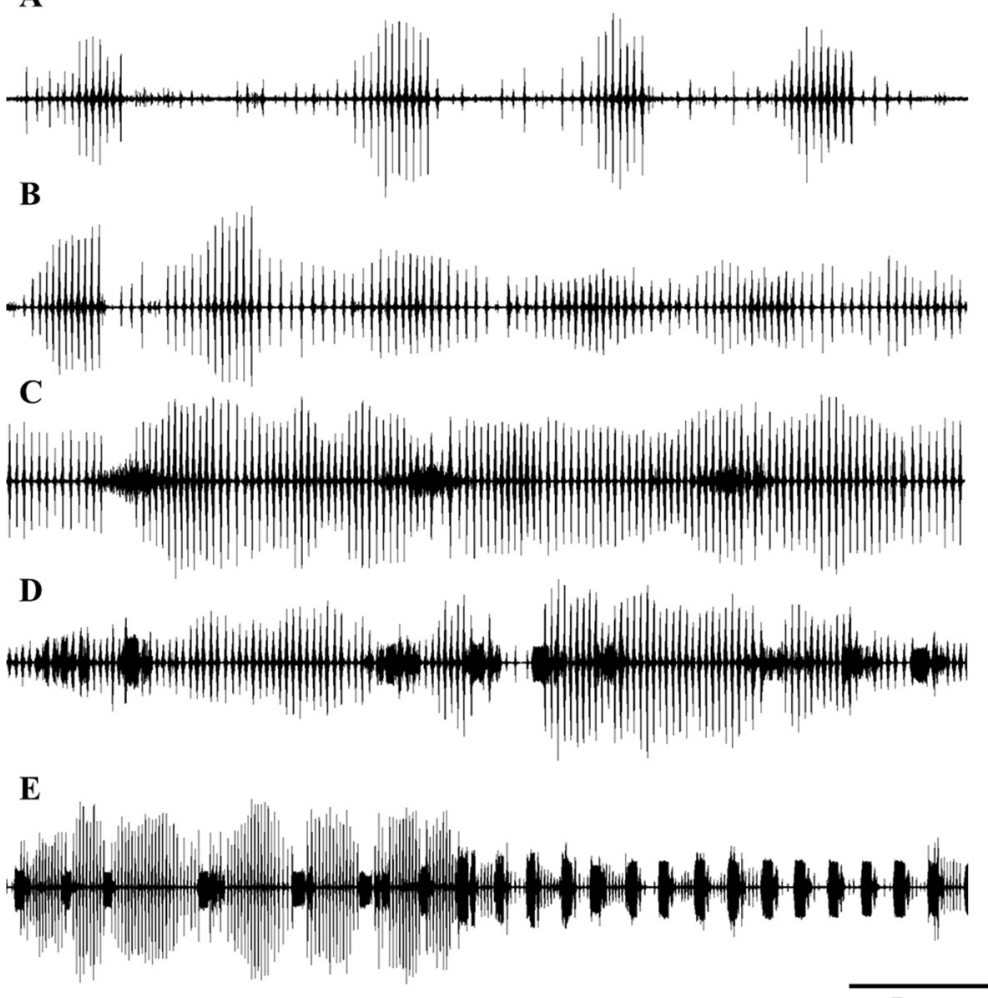

$5 \mathrm{~s}$

Fig. 4 Evolution of $C$. impicticornis FS-1 emissions in a female-female duet. (A) Readily repeated FS-1a pulse trains, (B) Sequence of single FS-1a pulses overlapping FS-1a pulse trains of the other female, (C, D) transition of FS-1a to FS-1b pulse train type, (E) inhibition of FS-1a pulses by readily repeated FS-1b pulse trains

in $C$. impicticornis than in C. ubica (repeated measures ANOVA, $\mathrm{F}_{1-186}=4.413, P=$ 0.037 and $\mathrm{F}_{1-177}=6.658, P=0.011$ ) (Fig. 5). On the other hand, mean difference in repetition time of pulse train between individuals of the same pair were higher in C. ubica (repeated measures ANOVA, $F_{1-186}=5.826, P=0.017$ ) (Figs. 2 and 5). No significant differences were found in mean differences of pulse train intervals between the species (repeated measures ANOVA, $\mathrm{F}_{1-186}=3.24, P=0.0747$ ) (Fig. 5). Analyses of variability of emission expressed by variation coefficients of signal parameters showed higher variability of repetition time and intervals between pulses trains in C. ubica (Fig. 5).

Males of both Chinavia species were silent during female vibratory interactions and responded only to FS-1a or FS-1b calls of the "winning" female (Fig. 1).

Synchronization of FS-1 pulses emitted by simultaneously calling E. heros females was less regular and within the same sequence signals often overlapped each other (Fig. 6). Female duetting did not inhibit male responses that often masked overlapped female calls and gave rise to vibratory complexes in which interference caused significant modification of input signal patterns (Fig. 6). Their spectral and temporal characteristics were furthermore changed by increased signal duration and frequency modification of masked emissions as reaction to avoid or minimize distortion of their 
Pulse train duration

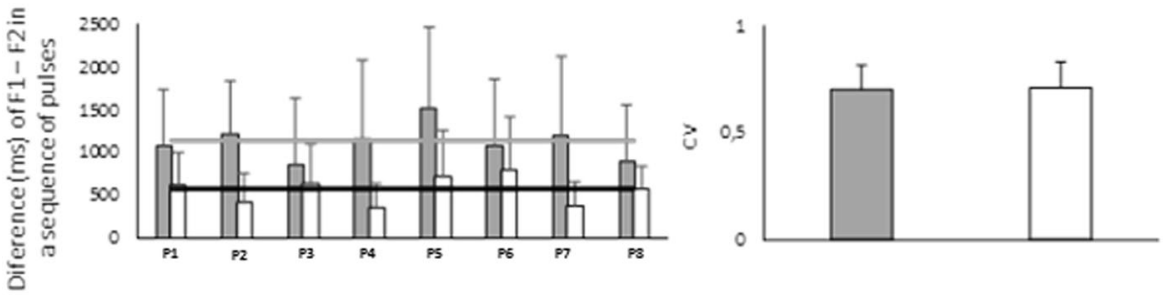

\section{Pulse train repetition time}
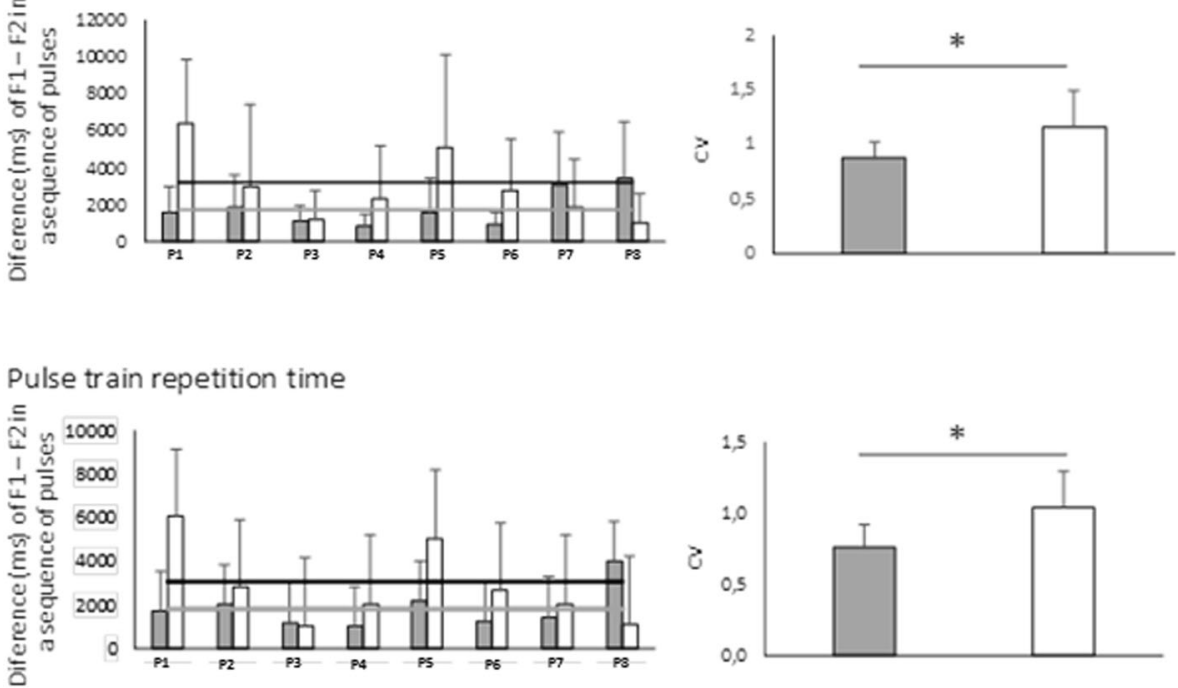

\section{Pulse train Dominant frequency}
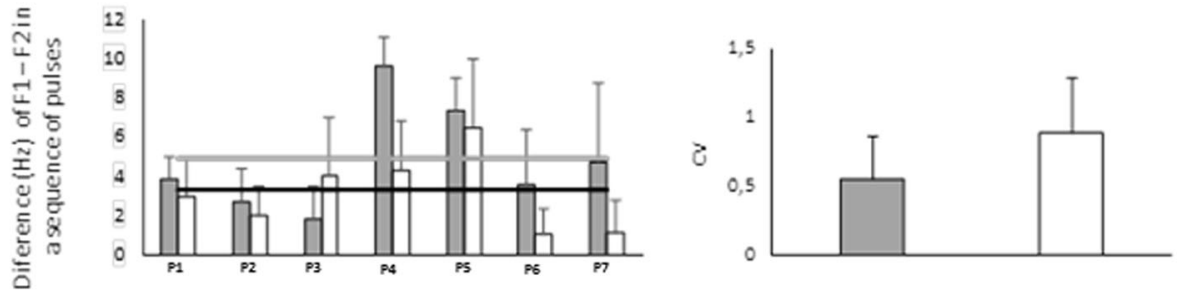

Fig. 5 Mean differences of temporal and spectral parameters of alternated FS-1 pulse trains emitted by two females (F1 and F2) in a sequence of 15 signals (left) and mean coefficient of variation (CV) of these variables (right). Bars indicate mean values, vertical lines above bars indicate SD and horizontal lines indicate mean values of differences between pairs for $C$. impicticornis (grey) and $C$. ubica (black). * indicates significant differences in $\mathrm{CV}(t$-test $\mathrm{P}<0.05)$. For dominant frequency, only seven pairs of females were considered because in each species these values showed discrepant values (outliers) related to the other pairs

signals (Fig. 6). Because of overlapped signals we were not able to to measure exactly temporal or spectral parameters of each individual signal emitted in the group with other female and the male. 
A
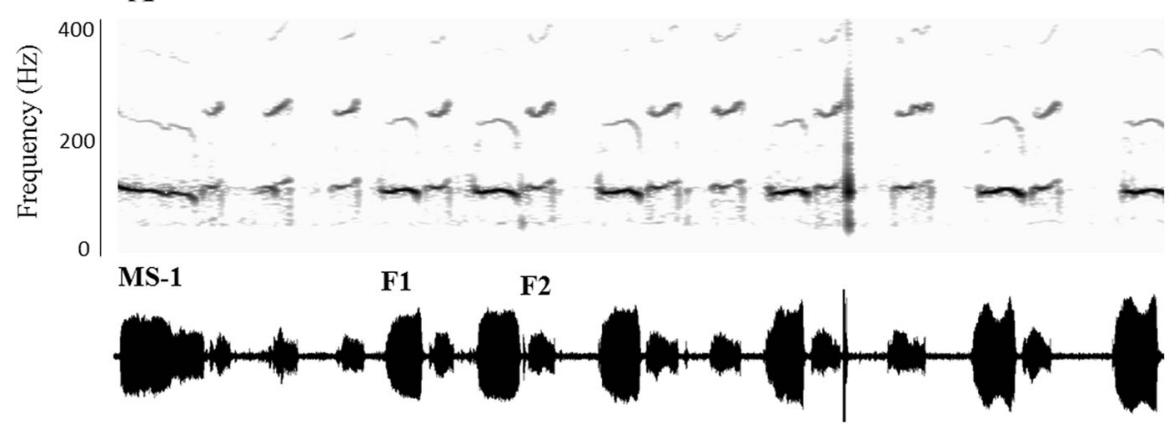

B

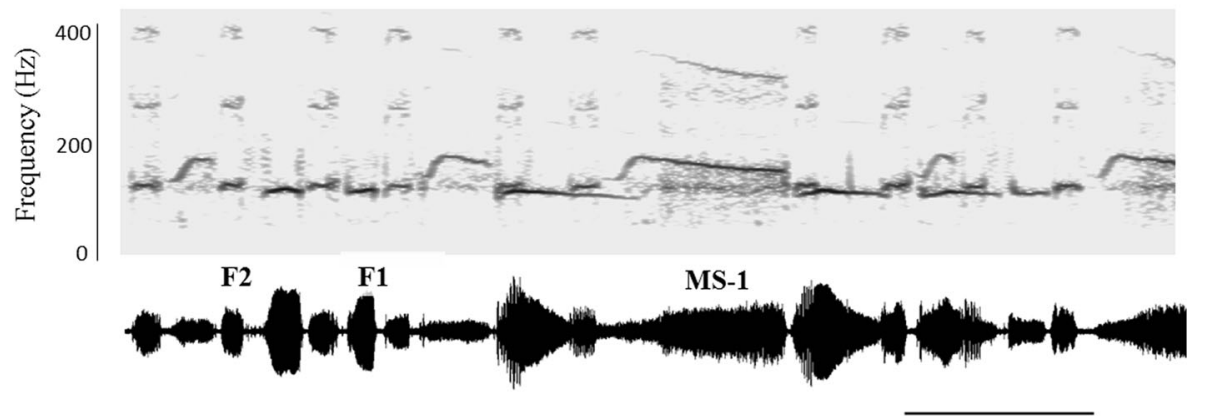

$10 \mathrm{~s}$

Fig. 6 Sonogram (upper trace) and oscillogram (lower trace) of E. heros female alternation with (A) nonmasked and (B) partly masked FS-1signals by male MS-1 responses. F1- female 1, F2 - female 2

\section{Female Rival Song}

Different from $C$. impicticornis that rivalry is expressed by female duets, C. ubica and E. heros females emit rival song (FRS) of characteristic and specific structure. The FRS of both species is characterized by frequency-modulated pulses grouped into irregularly repeated pulse trains of different duration that varies significantly among individuals (Table 1, Fig. 7).

FRS pulse trains produced by one of $C$. ubica duetting females inhibited the rival female emission of FS-1a or FS-1b pulse trains and triggered her to respond with FRS to form the rival duet (Fig. 7). Analyses of FRS temporal characteristics measured in three different C. ubica females have shown that pulse train duration increases linearly with increasing number of pulses (Online Resource ESM Fig. 1a). FRS pulse train duration values ranged between 5 (4 pulses/pulse train) and $57 \mathrm{~s}$ (34 pulses/pulse train) with majority of them shorter than $20 \mathrm{~s}$ (less than 20 pulses/pulse train). Pulse duration differs within the same pulse train and their distribution $(N=928)$ shows peaks between 700 and $1100 \mathrm{~ms}$ with shortest single values below 300 and longest above 3000 ms (Online Resource ESM Fig. 1b). Values of intervals between pulse train pulses exhibit uniform distribution between 50 and $400 \mathrm{~ms}$ with peak around $200 \mathrm{~ms}$ (Online Resource ESM Fig. 1c). Mean inter-pulse duration values varied significantly (One-way ANOVA, $F_{13,859}=4.911, P<0.001$ ) between 
Table 1 Temporal and spectral parameters (mean \pm SD) of Chinavia ubica and Euschistus heros female rivalry songs

\begin{tabular}{llc}
\hline Signal parameter & Chinavia ubica & Euschistus heros \\
\hline Pulse train & & \\
$\quad$ Duration (ms) & $13,222.64 \pm 9483.93$ & $12,890.75 \pm 5284.50$ \\
& $\left(\mathrm{~F}_{15-56}=0.59 P=0.87\right)$ & $\left(\mathrm{F}_{1-8}=0.08 P=0.78\right)$ \\
Pulses/pulse train & $11.34 \pm 6.40$ & $11.92 \pm 4.03$ \\
& $\left(\chi_{17}^{2}=70.77 P<0.001\right)$ & $\left(\chi_{1}^{2}=0.06 P=0.81\right)$ \\
Dominant frequency (Hz) & $101.93 \pm 9.42$ & $122.33 \pm 10.68$ \\
& $\left(\mathrm{~F}_{15-56}=17.59 \mathrm{P}<0.001\right)$ & $\left(\mathrm{F}_{1-8}=13.68 P<0.006\right)$ \\
Pulse & & \\
Duration (ms) & $964.81 \pm 324.67$ & $\left(\mathrm{~F}_{1-137}=14.03 \mathrm{P}<0.001\right)$ \\
& $\left(\mathrm{F}_{17-892}=6.74 \mathrm{P}<0.001\right)$ & $1000.05 \pm 215.60$ \\
Repetition time (ms) & $1195.61 \pm 352.48$ & $\left(\mathrm{~F}_{1-137}=0.012 P=0.91\right)$ \\
& $\left(\mathrm{F}_{17-892}=6.43 \mathrm{P}<0.001\right)$ & $259.42 \pm 111.44$ \\
Interval (ms) & $179.78 \pm 74.10$ & $\left(\mathrm{~F}_{1-137}=8.32 P=0.0045\right)$ \\
& $\left(\mathrm{F}_{17-892}=5.85 \mathrm{P}<0.001\right)$ & $116.43 \pm 12.01$ \\
Dominant Frequency $(\mathrm{Hz})$ & $122.44 \pm 45.66$ & $\left(\mathrm{~F}_{1-137}=126.5 \mathrm{P}<0.001\right)$ \\
& $\left(\mathrm{F}_{17-892}=6.80 \mathrm{P}<0.001\right)$ & \\
& &
\end{tabular}

Means were calculate from 16 individuals and 141 pulse trains and 18 individuals and 928 pulses for Chinavia ubica female rivalry songs and 2 individuals, 12 pulse trains and 141 pulses for Eushistus heros female rivalry songs. Differences between individuals of each species were calculated by repeated measures ANOVA and GLM with Poisson distribution for number of pulses/pulse train

minimal and maximal values at $138 \pm 83.7(N=14)$ and $234.3 \pm 114.7(N=78) \mathrm{ms}$ respectively.

The dominant frequency of 948 analyzed pulses of $C$. ubica FRS was distributed between 72 and $117 \mathrm{~Hz}$ (Online Resource ESM Fig. 1d). Mean pulse dominant frequencies varied in FRS signals $(N=11)$ between minimal and maximal values at $87.1 \pm 6.5(N=16)$ and $114.1 \pm 2.0(N=89) \mathrm{Hz}$, respectively. FRS pulses show characteristic downward oriented frequency modulation sweep (Fig. 7) distributed within two distinct groups in pulses shorter than $1500 \mathrm{~ms}$ (Online Resource ESM Fig. 1e). Frequency decay of the first group (Fig. S1E) ranges between 10 and $55 \mathrm{~Hz}$ $/ 100 \mathrm{~ms}$ for pulses of upper frequency between $109.4 \pm 2.3(N=32)$ and $123 \pm 2.8$ $(N=57) \mathrm{Hz}$, and that of the second group (Fig. S1E) ranges below $10 \mathrm{~Hz} / 100 \mathrm{~ms}$ for pulses with upper frequency between $91.54 \pm 1.44(N=24)$ and $101.5 \pm 2.66(N=$ 28).

FRS signals emitted by E. heros differ significantly from FS-1 and MS-1 pulses by their temporal characteristics as well as by FM downward oriented frequency sweep (Fig. 7, Table 1). Pulse train duration varied between individuals (Table 1) and according to the number of pulses per pulse train between minimal and maximal single values at 5851 (5 pulses/pulse train) and 17,809 ms (16 pulses/pulse train) respectively. Pulse duration, interval and dominant frequency means differ significantly between individuals of two analysed groups contrary to pulse repetition time that was not significantly different for all pulses. E. heros FRS pulses show chracteristic FM with downward oriented frequency sweep from values around 127 to $103 \mathrm{~Hz}$ in the first 

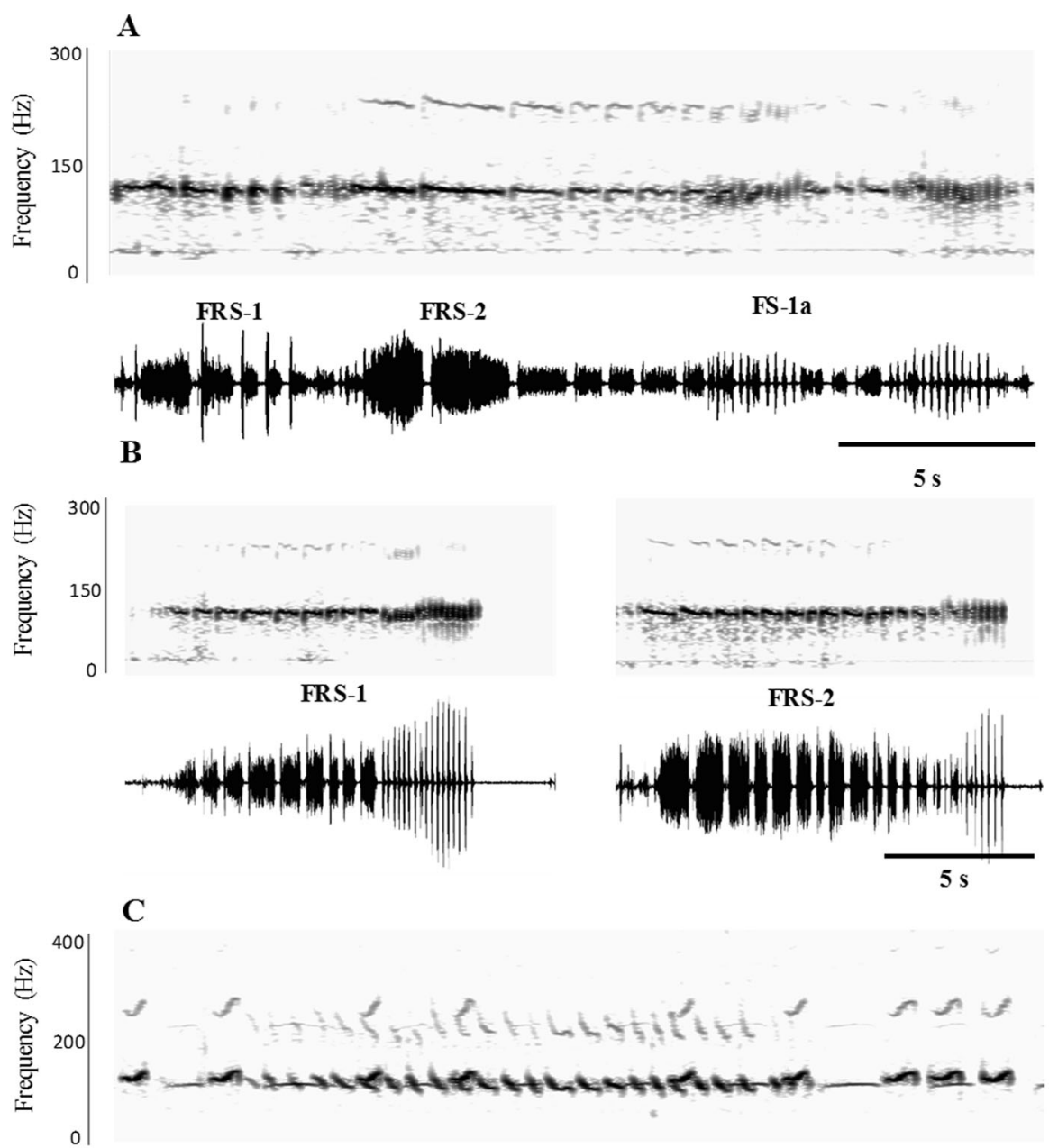

F-1 F-2

FRS

F-2
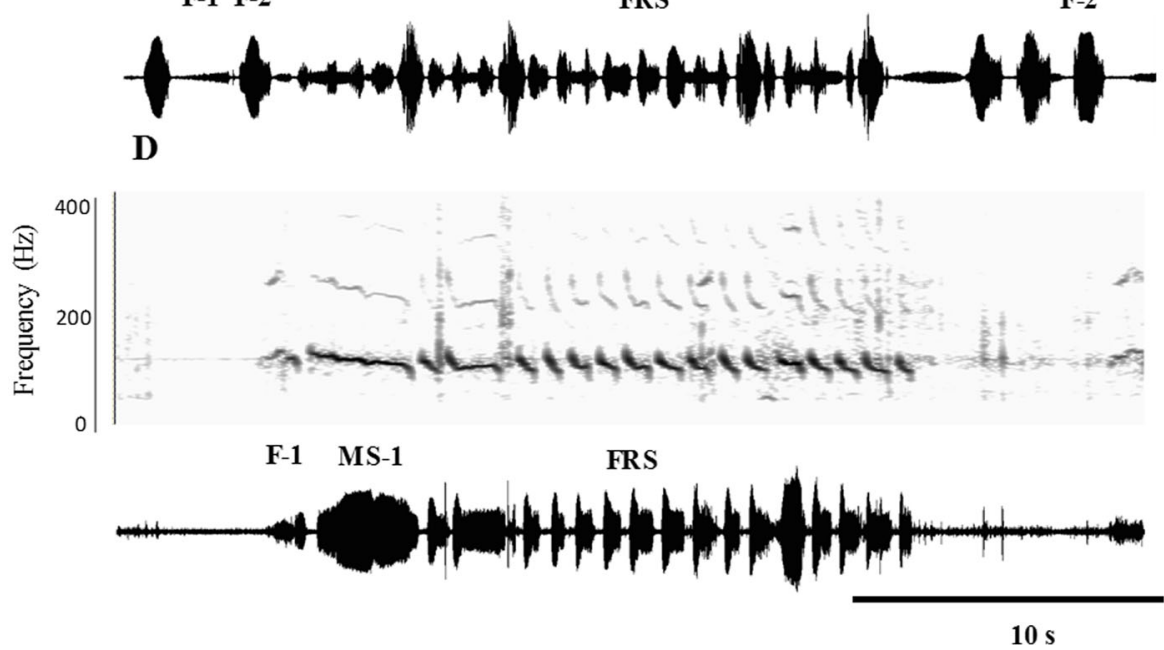
Fig. 7 Sonogram (upper trace) and oscillogram (lower trace) of $C$ ubica (A, B) and E. heros (C, D) female rival song (FRS) shown at different time scales. (A) Sequence of FRS pulse train duet with FS-1a emitted by the third female on a plant. (B) Two examples of FRS pulse trains, (C) and (D) E. heros FRS pulse trains connected with FS-1/MS-1 (C) and FS-1/FS-1 duets (D)

group and from 165 to $129 \mathrm{~Hz}$ in the second group showing mean sweep value of 4.6 and $4.3 \mathrm{~Hz} / 100 \mathrm{~ms}$ respectively.

\section{Discussion}

In contrast to vertebrates, vibratory communication networks have been less studied in insects. Most investigations have been focused on group living species (Cocroft and Hamel 2010) and on interactions between males in a group during reproductive behavior (Virant-Doberlet et al. 2014).

Comparative studies of communication in the calling phase of mating behavior, conducted in more than 36 stink bug species point out several exceptions and various opened questions about the basic pattern of information exchange. Spontaneous calling of a single male on a plant was recorded for example in Thyanta perditor (Fabricius 1794) (Blassioli-Moraes et al. 2005), Nezara viridula (Linnaeus 1758) (Zgonik and Čokl 2014) and Chlorochroa uhleri (Stål 1872) (Bagwell et al. 2008). The role of the second type of the female calling song has not been clarified yet in $N$. viridula (Čokl et al. 2000) and species like Dichelops melacanthus (Dallas 1851) Blassioli-Moraes et al. 2014), C. impicticornis and C. ubica (Laumann et al. 2016). In Edessa meditabunda (Fabricius, 1794) for example starts the calling phase of mating behavior by emission of the first male song (MS1) and female responses are triggered by the male second song (MS2) emitted during courtship (Silva et al. 2012). Finally, female songs have not been recorded in several stinkbug species (Gogala and Razpotnik 1974; Shestakov 2015). Most investigations of communication between a single female and male were conducted using standardized protocol that enabled comparison of signals between different species, but ignored communication between conspecific individuals in a group.

The female calling song as highly autonomous and stable sequence of readily repeated uniform signals emitted from one place on a plant mediates among others information on the directionality of male movement to the female (Virant-Doberlet et al. 2006). To avoid signal overlapping males of species like $N$. viridula (Čokl et al. 2000), C. impicticornis, C. ubica (Laumann et al. 2016) respond to the calling female with vibratory signals emitted within interval between two consecutive female calls, that enables formation of well coordinated duets. On the other hand, masked female and male vibratory emissions have been recorded in D. melacanthus (Blassioli-Moraes et al. 2014) and different mechanisms to minimize consequences of interference occurring as consequence of overlapped vibrations have been described in E. heros (Čokl et al. 2015).

Our results bring several responses to above mentioned opened questions. Here we demonstrated as first among Pentatomidae, that: (1) a male triggers simultaneous emission of the calling song in several females, (2) females synchronize calling signals in the coordinated one-to-one alternation pattern and, (3) female rivalry runs by 
exchange of different types of calling song signals that includes modification of song temporal characteristics and emission of the rival song.

Synchronization of calling emissions could have several advantages as enhancing group detection or confusing predators (McGregor and Peake 2000). Notwithstanding, to reach this conclusion it is necessary to clearly demonstrate that females in synchronized choruses give some advantage (Greenfield 1994). The evolution of duets with synchronized calling signals of different temporal and frequency characteristics suggests direct female rivalry interactions of studied model stink bug species.

Rivalry interactions with vibrational signals have been until now described in malemale interactions. However, Percy and Day (2005) described alternation of female calling in the leafhoppers (Hemiptera: Cicadellidae) Stenocotis depressa (Walker) and Austrolopa brunensis Evans being similar to the one shown in our study for stinkbugs females.

The repertory of stinkbug female rivalry interactions observed as synchronized signalling, exchange of different types of calling song signals and emission of the female rival song is more complex than the one reported for male/male stink bug interactions. In the latter interactions, males express rivalry only by exchanging of rival song pulses in a-b-a-b sequence (Čokl et al. 2000, 2011; Blassioli-Moraes et al. 2005; Bagwell et al. 2008).

All described female rivalry interactions are included in the pattern of network interactions in sexual vibratory communication of arthropods. The stink bug rivalry communication is similar to the one described for male interactions of others taxa. In a review, Virant-Doberlet et al. (2014) identified at least one of such responses in malemale interactions in Crustacea, Araneae, and Insecta. In insects, such interactions have been observed principally in Hemiptera (Cercopidae, Cicadellidae, Membracidae, Delphacidae and Flatidae) and Diptera (Chloropidae and Cypelosomatidae).

Synchronization of alternated calling song signals is best expressed in duetting C. impicticornis females because of constant differences in repetition time between both females. The better-structured female duets in $C$. impicticornis could be related to the absence of the specific rival song. Simultaneous female calling inhibits male responding in C. impicticornis and C. ubica but not in E. heros; in the latter species male responses often overlap alternated female calling signals and mates singing in a group need to contrast their emissions by modification of their temporal and spectral characteristics. The relevance of these modifications depends on the potential of the sensory system to code and process temporal and FM changes within the complex vibrational signal. Studies concerning this problem have not been conducted yet at sensory and underlying neuronal network level. We hypothesize that phase coupled response pattern of low frequency vibratory receptor neurons described in the model species $N$. viridula (Čokl 1983; Čokl et al. 2006; Zorović et al. 2008; Zorović 2011) enables precise frequency discrimination in the frequency range characteristic for stinkbug vibratory communication signals.

Further evolution of female rivalry differs in the three studied species. C. impicticornis females display rivalry by transition from one to another type of the calling song that at different stages silences the competing one. The rivalry between $C$. ubica females differs by the emission of the rival song that replaces duets with the second type of the calling song. FRS duets carry basic characteristics of male one-to-one exchange of rival song signals described in several stink bug species (Čokl et al. 2017). Males of both species are silent during conspecific female rivalry to avoid overlapping synchronized emissions by 
long responses produced within short intervals between female duetting signals. Female rivalry expressed in E. heros by FS-1 duets and emission of the FRS seems to be less effective because it does not silence other female or male singing as described in both Chinavia species. The vibratory communication interplay between females and the male are further complicated by overlapping of signals with similar frequency characteristics that lead to interference and reactions to minimize its effects as change in time parameters and increase the frequency difference between signals by changing the frequency level and the frequency modulation pattern (Čokl et al. 2015). Vibrational communication of grouped $E$. heros females and males needs further investigation to understand better the role and evolution of species signals within different behavioral contexts.

Compared with Chinavia species female/male pairs (Laumann et al. 2016) we observed a reduction of mattings in grouped individuals as result of described rivalry interactions. Copulation was observed in $41.67 \%$ in C. impicticornis and in $54.17 \%$ in C. ubica groups. Laumann et al. (2016) reported successful copulations in $81.25 \%$ of C. impicticornis and $76.0 \%$ of C. ubica observed couples. On the other hand, it appears that females/male group interactions do not significantly decrease or inhibit copulation in E. heros: copulation was observed in $78.94 \%$ of the groups and in $85.0 \%$ in single female/male couples (data not published).

Differences between species suggest differential evolution of communication systems in stink bugs of different clades that leads to different adaptation to communicate in network conditions. Group singing Chinavia females clearly show disruptive interference during mating behavior with characteristically expressed rivalry. On the other hand, it seems that $E$. heros females are less affected by rivalry interactions. This could be related to the efficient response mechanisms to avoid or minimize the interference effect of overlapped signals (Čokl et al. 2015). This adaptive effect may have ecological consequences and could help to explain high population levels of E. heros in agricultural areas and their often observed aggregations on the same and/or neighbouring plants (Higuchi 1992; Panizzi and Lucini 2016; Aquino 2016). In contrast, Chinavia spp. are usually found at low population densities in natural and agroecosystems (Panizzi et al. 2000; Panizzi and Lucini 2016).

Results of the present study explain the role of different types of the female calling song signals. In both Chinavia species, FS-1b pulse trains represent emission at higher level of the courtship phase (Laumann et al. 2016) and play an important role in female rivalry. Rivalry function of the second female song can be expected also in other species. In the red-banded stink bug Piezodorus guildinii (Westwood, 1837) the second female song was recorded in females staying alone or together with another female on a loudspeaker membrane (Blassioli-Moraes et al. 2005). In red-shouldered stinkbug T. perditor were long FS-2 pulses recorded only by females in the absence of a male (Blassioli-Moraes et al. 2005) and in N. viridula the second type of the female calling song pulse trains were recorded only occasionally in a female male couple without explanation of their role ( $\breve{C o k l}$ et al. 2000).

In conclusion, the present study gives a new insight into the early phase of stink bug communication in natural conditions where we can expect chemical and vibratory interactions between numerous conspecific and alien species males and females. Our results on rivalry behavior and communication between females open the question on the role of until now mostly ignored signals with intermediate temporal and spectral characteristics. Finally, we need more information on the calling function of plant- 
borne chemical signals, like footprints, that may replace calling function of female vibratory emissions lacking in some stinkbug species.

Acknowledgements Thanks go to Maycon Vinicius Laia Aquino for help with insect rearing. The National Council for Scientific and Technological Development (CNPq) supports M. Borges, M.C. B- Moares and R. Laumann with productivity grants. The Brazilian Agricultural Research Corporation (EMBRAPA) and The National Council for Scientific and Technological Development (CNPq) support long-term research at Semiochemicals Laboratory with grants. This work was supported by the Research Support Foundation of the Federal District (FAP-DF, Project 193.000.978/2015) and the Slovenian National Research Agency (Research Program No. P1-0255). Aline Moreira Dias received financial support through a grant from the Coordination of Superior Level Staff Improving (CAPES).

\section{Compliance with Ethical Standards}

Conflict of Interest The authors declare that they have no conflict of interest.

\section{References}

Aquino MFS (2016) Interações de percevejos e parasitoides de adultos no sistema de cultura da Soja. Dissertation, Universidade de Brasília

Bagwell GJ, Čokl A, Millar JG (2008) Characterization and comparison of substrate-borne vibrational signals of Chlorochroa uhleri, Chlorochroa ligata and Chlorochroa sayi (Heteroptera: Pentatomidae). Ann Entomol Soc Am 101:235-246

Blassioli-Moraes MC, Laumann RA, Čokl A, Borges M (2005) Vibratory signals of four Neotropical bug species. Physiol Entomol 30:175-188

Blassioli-Moraes MC, Magalhaes DM, Čokl A, Laumann RA, da Silva JP, Silva CCA, Borges M (2014) Vibrational communication and mating behaviour of Dichelops melacanthus (Hemiptera: Pentatomidae) recorded from loudspeaker membranes and plants. Physiol Entomol 39:1-11

Borges M, Blassioli-Moraes MC (2017) The semiochemistry of Pentatomidae. In: Čokl A, Borges M (eds) Stink bugs biorational control based on communication processes. CRC Press, Boca Raton, pp 95-124

Borges M, Jepson P, Howse P (1987) Long-range mate location and close-range courtship behaviour of the green stink bug, Nezara viridula and its mediation by sex pheromones. Entomol Rev 44:205-212

Bradbury JW, Vehrencamp SL (2011) Principles of animal communication, 2nd edn. Sinauer Associates Inc. Publishers, Sunderland

Broughton WB (1963) Methods in bio-acoustic terminology. In: Busnel RG (ed) Acoustic behaviour of animals. Elsevier Publishing Company, Amsterdam London New York, pp 3-24

Cocroft RB, Hamel JA (2010) Vibrational communication in the "other" social insects: a diversity of ecology, signals and signal function. In: O'Connell-Rodwell CE (ed) vibrational communication in animals. Transworld research network, Kerala, pp 47-68

Čokl A (1983) Functional properties of vibroreceptors in the legs of Nezara viridula (L.) (Heteroptera: Pentatomidae). J Comp Physiol A 150:261-269

Čokl A, Virant-Doberlet M, Stritih N (2000) Structure and function of songs emitted by southern green stink bugs from Brazil, Florida, Italy and Slovenia. Physiol Entomol 25:1-10

Čokl A, Virant-Doberlet M, Zorović M (2006) Sense organs involved in vibratory communication in bugs. In: Drosopoulos E, Claridge MF (eds) Insect sounds and communication. CRC Press, Boca Raton London New York, pp 71-80

Čokl A, Žunič A, Virant-Doberlet M (2011) Predatory bug Picromerus bidens communicates at different frequency levels. Central Eur. J Biol 6:431-439

Čokl A, Laumann RA, Žunič-Kosi A, Blassioli-Moraes MC, Virant-Doberlet M, Borges M (2015) Interference of overlapping insect vibratory communication signals: an Eushistus heros model. PLoS One 10:1-16 
Čokl A, Laumann RA, Stritih N (2017) Substrate-borne vibratory communication. In: Čokl A, Borges M (eds) Stink bugs: biorational control based on communication processes. CRC Press, Boca Raton, pp 125-164

Fehr WR, Caviness CE, Burmood DT, Pennington JS (1971) Stage of development descriptions for soybeans, Glycine max (L.) Merrill. Crop Sci 11:929-931

Gogala M, Razpotnik R (1974) Methods of oscillographic analysis for research in bioacoustics. Biološki vestnik 22:209-216

Grazia J, Panizzi AR, Greve C, Schwertner CF, Campos LA, Garbelotto TA, Fernandes JAM (2015) Stink bugs (Pentatomidae). In: Panizzi AR, Grazia J (eds) True bugs (Heteroptera) of the Neotropics. Springer, Dordrecht, pp 681-756

Greenfield MD (1994) Synchronous and alternating choruses in insects and anurans: common mechanisms and diverse functions. Am Zool 34:605-615

Haccou P, Meelis E (1992) Statistical analysis of behavioural data: an approach based on time-structured models. Oxford University Press, Oxford

Higuchi H (1992) Population prevalence of occurrence and spatial distribution of Piezodorus hybneri adults (Heteroptera: Pentatomidae) on soybeans. Appl Entomol Zool 27:363-369

Kavčič A, Čokl A, Laumann RA, Blassioli-Moraes MC, Borges M (2013) Tremulatory and abdomen vibration signals enable communication through air in the stink bug Euschistus heros. PLoS One 8:1-10

Laumann RA, Čokl A, Blassioli-Moraes MC, Borges M (2016) Vibratory communication and its relevance to reproductive isolation in two sympatric species (Hemiptera: Pentatomidae: Pentatominae). J Insect Behav 29:643-665

McGregor PK, Peake TM (2000) Communication networks: social environments for receiving and signalling behaviour. Acta Ethol 2:71-81

Panizzi AR (2013) History and contemporary perspectives of the integrated pest management of soybean in Brazil. Neotrop Entomol 42:119-127

Panizzi AR, Lucini T (2016) What happened to Nezara viridula (L.) in the Americas? Possible reasons to explain populations decline. Neotrop Entomol 45:619-628

Panizzi AR, McPherson JE, James DG, Javahery M, McPherson RM (2000) Stink bugs (Pentatomidae). In: Schaefer CW, Panizzi AR (eds) Heteroptera of economic importance. CRC Press, Boca Raton, pp 421474

Percy DM, Day MF (2005) Observations of unusual acoustic behaviour in two Australian leafhoppers (Hemiptera; Cicadellidae). J Nat Hist 39:3407-3417

Pinter-Wollman N, Hobson EA, Smith JE, Edelman AJ, Shizuka D, de Silva S, Waters JS, Prager SD, Sasaki T, Wittemyer G, Fewell J, McDonald DB (2014) The dynamics of animal social networks: analytical, conceptual, and theoretical advances. Behav Ecol 25:242-255

R Development Core Team (2011). R: A language and environment for statistical computing. R Foundation for Statistical Computing. http://www.R-project.org/, Vienna

Shestakov LS (2015) A comparative analysis of vibrational signals in 16 sympatric species (Pentatomidae, Heteroptera). Entomol Rev 95:310-325

Silva ACA, Laumann RA, Ferreira JBC, Blassioli-Moraes MC, Borges M, Čokl A (2012) Reproductive biology, mating behaviour and vibratory communication of the brown-winged stink bug, Edessa meditabunda (Fabr.) (Heteroptera: Pentatomidae). Psyche 2012:1-9

Tillman PG, Northfield TD, Mizell RF, Riddle TC (2009) Spatiotemporal patterns and dispersal of stink bugs (Heteroptera: Pentatomidae) in peanut-cottonfarmscapes. Env Entomol 38:1038-1052

Virant-Doberlet M, Čokl A, Zorović M (2006) Use of substrate vibrations for orientation: from behaviour to physiology. In: Drosopoulos S, Claridge MF (eds) Insect sounds and communication. CRC Press, Boca Raton, pp 81-97

Virant-Doberlet M, Mazzoni V, De Groot M, Polajnar J, Lucchi A, Symondson WOC, Čokl A (2014) Vibrational communication networks: eavesdropping and biotic noise. In: Cocroft R, Gogala M, PSM H, Wessel A (eds) (2014) studying vibrational communication. Springer-Verlag, Berlin Heidelberg, pp 93-123

Zgonik V, Čokl A (2014) The role of signals of different modalities in initiating vibratory communication in Nezara viridula. Central Eur. J Biol 9:200-211

Zorović M (2011) Temporal processing of vibratory communication signals at the level of ascending interneurons in Nezara viridula (Hemiptera: Pentatomidae). PLoS One 6:1-8

Zorović M, Prešern J, Čokl A (2008) Morphology and physiology of vibratory interneurons in the thoracic ganglia of the southern green stinkbug Nezara viridula (L.) J Comp Neurol 508:365-381 